\title{
Copper Oxide Nanoparticles Stimulate Cytotoxicity and Apoptosis in Glial Cancer Cell Line
}

\author{
Nasim Rahmani Kukia ${ }^{1}$, Ardeshir Abbasi ${ }^{2}$ and Seyyed Maysam Abtahi Froushani ${ }^{1}$ \\ ${ }^{1}$ Department of Microbiology, Faculty of Veterinary Medicine, Urmia University, Urmia, Iran \\ ${ }^{2}$ Departmentof Immunology, Tarbiat Modares University of Medical Sciences, Tehran, Iran
}

(Received: 13 March, 2017; Accepted: 29 April, 2018; Published (web): 10 June, 2018)

\begin{abstract}
Due to cytotoxic potential, Copper Oxide Nanoparticles (CuO NPs) have recently been studied in various in vivo and in culture cell line. Also, $\mathrm{CuO}$ has received much attention in cancer therapy. We aimed to evaluate the cytotoxicity of $\mathrm{CuO}$ NPs on glial cancer (B92) cell line. B92 cancer cells were cultured with CuO NPs at different concentrations $(5,10$, and $20 \mu \mathrm{g} / \mathrm{ml})$ with 30 and $60 \mathrm{~nm}$ particle size. Then, cancer cells were incubated for $24 \mathrm{hrs}$. The apoptosis and cytotoxicity of cells were estimated by acridine orange/propidium iodide staining and MTT assay, respectively. Both sizes of CuO NPs had cytotoxic effect. Even with the lowest concentration, the cytotoxic impact accommodated $32 \%$ of cell apoptosis with $30 \mathrm{~nm}$ size. When the concentration of CuO NPs increased, viability decreased and apoptosis increased. However, these amounts have no significant changes in the concentration of 10 to $20 \mu \mathrm{g} / \mathrm{ml}$ between two particle sizes $\left(30\right.$ and $60 \mathrm{~nm}$ ). The $\mathrm{IC}_{50}$ was decreased as the size of particles increased, but there was no significant change. This finding suggests that exposure to CuO NPs had significant cytotoxic effect with the sizes tested when compared to unexposed control in a way that the smaller size and higher concentration exerted the maximum cytotoxic effects. It seems that augmentation may not have any impact on their in vitro cytotoxicity.
\end{abstract}

Key words: B92 cancer cells, Copper Oxide Nanoparticles, Cytotoxicity, Apoptosis, Glial.

\section{INTRODUCTION}

Nanoparticles (NPs) are usually a group of nanoscale materials with a range from 1 to $100 \mathrm{~nm}$. Inorganic NPs consisting of metal oxides have been manufactured on a large scale for applications in medicine like drug delivery, bio-sensing, cell imaging and cancer therapy in organs such as brain which is protected by specialized brain barrier. ${ }^{1-4}$ Chemotherapeutic researches based on the use of metals for new anti-cancer drugs with the potential of being less toxic and exhibiting more anti-proliferative activity against tumors have been developed. ${ }^{5}$ NPs in comparison to large biological molecules (enzymes, receptors, etc.) can easily display specific interactions with biomolecules and may be useful in cancer diagnosis and treatment. ${ }^{6,7}$ Due to their antimicrobial

Correspondence to: ArdeshirAbbasi Email: ardeshir.abbasi66@gmail.com mailto: meysamabtahi@ hotmail.com properties, copper oxide $(\mathrm{CuO})$ NPs are intentionally widely manufactured and used in plastics, paints, food containers. ${ }^{8}$

Various studies have reported an increased cytotoxic and genotoxic potential as well as an intense pro-inflammatory responses of $\mathrm{CuO}$ NPs in $v^{2}{ }^{9} o^{9,10}$ and in cultured cell lines. ${ }^{11-15}$ Oxidative stress is often used to describe the toxicity of cells associated with particle exposure. Because of their unique features such as size, morphology, solubility, surface area as well as their ability to associate with biomolecules from the environment to form a protein and interactions of the particles with cellular membranes, uptake and intracellular bioavailability, can finally lead to elevated levels of reactive oxygen species (ROS). ${ }^{5} \mathrm{CuO}$ NPs are able to generate oxidative stress and significantly decrease cell viability in tumor cells. ${ }^{16-18}$ 
Glioma is a type of brain and central nervous system tumors, which starts in supportive glial cells that surround nerve cells and help them function. ${ }^{19}$ Cell division is a normal process to build new cells and tissues but it is stopped whenever there is no longer need for more cells or is a threat for the organisms to be destroyed by apoptotic cell death. The ability of cancer cells to continue reproducing, spreading and avoiding apoptosis are the basic properties of tumors, therefore, inducing apoptosis in cancer cells is a major desire for researchers in the field of tumor treatments. ${ }^{20}$ Even several recent studies evaluated cytotoxic effects of metal and metal-containing material components on glioma cancer cell lines, ${ }^{15,21,22}$ the consequences of exposure of $\mathrm{CuO}$ NPs with B92 cancer cells have not yet been reported.

Therefore, we designed to determine the concentration and size-dependent effects of CuONPs exposure in B92 cancer cells.

\section{MATERIALS AND METHODS}

Synthesis and characterization of $\mathrm{CuO}$ nanoparticles. To synthesis colloidal suspension of $\mathrm{CuO}$ NPs (30 and $60 \mathrm{~nm}$ ), we used an alcothermal method with minor modifications. To $100 \mathrm{ml}$ of distilled water, we added $0.25 \mathrm{~g}$ of $\mathrm{CuSO}_{4}$ and then 5 $\mathrm{g}$ of polyvinyl pyrrolidone K30 (PVP-K30) and was dissolved in this solution. For reduction of $\mathrm{CuO}$, $0.25 \mathrm{~g} \mathrm{NaBH}_{4}$ was poured into the solution. The solution of $\mathrm{CuSO}_{4}$ turned from blue to green immediately and finally a brown colored product was obtained. After $30 \mathrm{~min}$, required quantities of ascorbic acid was added and kept in a water bath at $60{ }^{\circ} \mathrm{C}$ for $30 \mathrm{~min}$. The precipitates were washed with ethanol and centrifuged (4000 g, $15 \mathrm{~min}$ ) and finally, $\mathrm{CuO}$ NPs colloid powder was obtained and stored for further use. A Different amount of ascorbic acid was used to produce $\mathrm{CuO}$ NPs with different sizes. Structural studies of $\mathrm{CuO}$ NPs were done via scanning electron microscopy (SEM) (TESCAN 510 Czech Republic) and dynamic light scattering (DLS) (Nano-zetasizer MALVERN. England).
Cell culture and treatment. B92 rat cancer cell line was purchased from National Cell Bank of Iran (NCBI, Tehran, Iran) and was cultured in $75 \mathrm{~cm}^{2}$ flask at the density of $6 \times 10^{4}$ cells $/ \mathrm{cm}^{2}$ in RPMI 1640, supplemented with $100 \mathrm{ug} / \mathrm{mL}$ penicillin and $100 \mu \mathrm{g} / \mathrm{mL}$ streptomycin and $10 \%$ heat-inactivated FBS at $37^{\circ} \mathrm{C}$ and $5 \% \mathrm{CO}_{2}$ to reach $80 \%$ confluency. Cells were harvested using $0.25 \%$ trypsin and were sub-cultured into $75 \mathrm{~cm}^{2}$ flasks, 6-well plates or 96 well plate; they were allowed to recover for 24-hrs prior to treatment. Particles were suspended in cell culture medium by pulse sonication for $5 \mathrm{~min}$ to avoid particle agglomeration. A serial dilution was established by mixing equal volumes of particle suspension and cell culture medium.

Cell cytotoxicity assay. The viability of B92 cancer cells was assessed by the MTT assay as described before. ${ }^{23}$ Briefly, $1 \times 10^{4}$ cells/well were seeded in 96-well plates and exposed to CuO NPs at the concentrations of 0 (as a control), 5, 10, and 20 $\mu \mathrm{g} / \mathrm{mL}$ for $24 \mathrm{hrs}$. Twenty microliters of a $5 \mathrm{mg} / \mathrm{mL}$ solution of MTT in PBS was added to each well, and the plates were incubated at $37^{\circ} \mathrm{C}$ in $5 \% \mathrm{CO}_{2}$ for 4 hrs. The medium was then carefully removed, and the purple products were dissolved in $0.1 \mathrm{~mL}$ dimethyl sulfoxide (DMSO). The plates were shaken for 10 min, and the optical density (OD) of the dissolved solute measured by an ELISA reader (Dynatech, Denkendorf, Germany) at $570 \mathrm{~nm}$.

Detection of apoptosis by acridine orange and propidium iodide. Cells were cultured in a 6 well plates at a concentration of $1 \times 10^{6}$ cells/well and allowed for $24 \mathrm{hrs}$ adherence. Cells were treated with different concentrations of CuONPs $(0,5,10$ and 20 $\mu \mathrm{g} / \mathrm{ml}$ ) for $24 \mathrm{hrs}$. The suspension was discarded and the cells were washed twice with phosphate buffered saline (PBS). Staining with $10 \mu \mathrm{l}$ of Acridine Orange (AO, Sigma Aldrich $10 \mu \mathrm{g} / \mathrm{ml}$ ) was performed for 15 min at room temperature in dark and immediately before fluorescence microscopic studies, $10 \mu \mathrm{l}$ Propidium Iodide (PI) (Sigma Aldrich) was added to the cellular pellet. Apoptotic modification in B92 cancer cells was determined in an improved Neubauer rhodium hemocytometer under fluorescent 
microscopy and the percentage of cells exhibiting apoptosis was counted and calculated.

Statistical analysis. Statistical significance was performed by Student's t-test and one-way analysis of variance. Data were presented as mean $\pm \mathrm{SD}$ and $p<0.05$ was considered as the level of significance for all analyses performed.

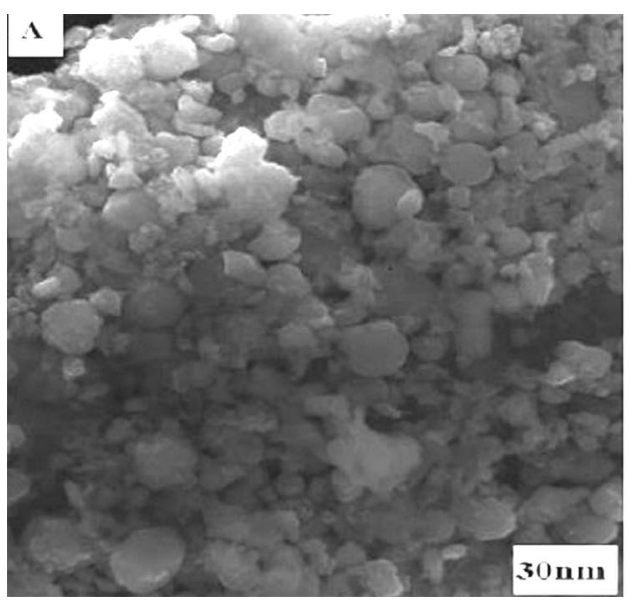

Figure 1. Structural characterization of synthesized $\mathrm{CuO}$ NPs by field emission scanning electron. A) $\mathrm{CuO}$ NPs with $30 \mathrm{~nm}$ sizes. B) $\mathrm{CuO}$ NPs with $60 \mathrm{~nm}$ sizes.
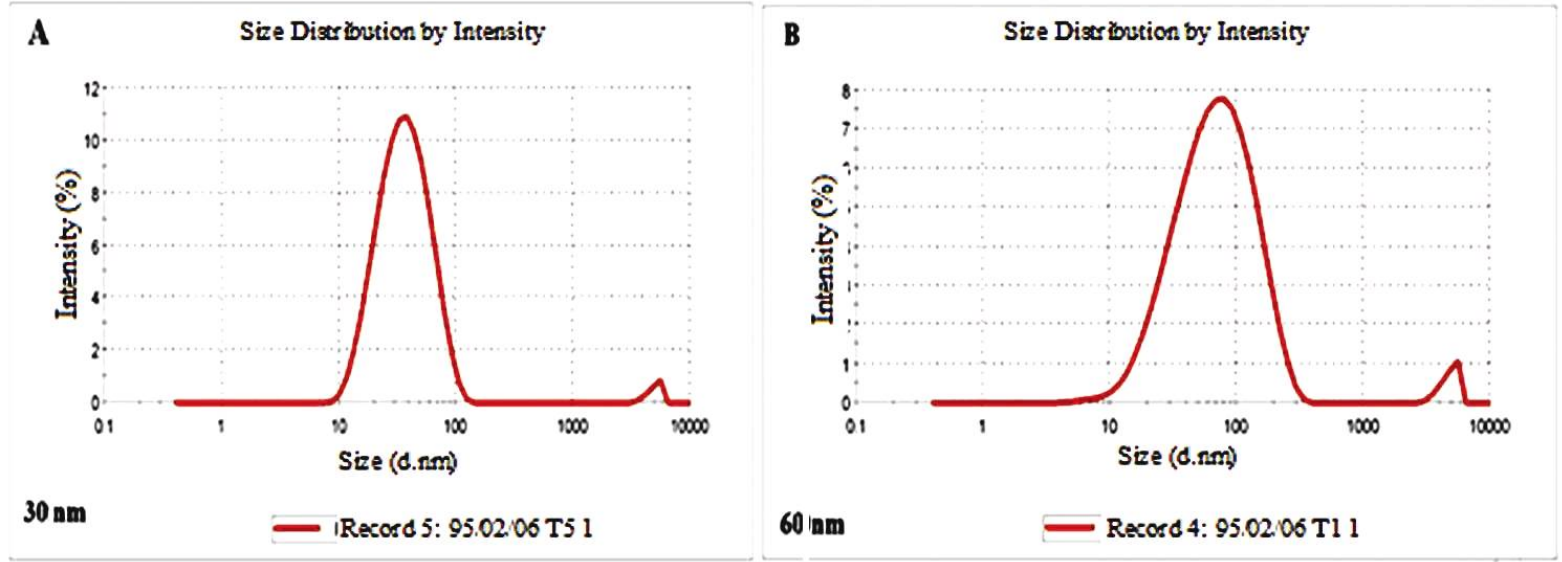

$30 \mathrm{~nm}$

- IRecord 5: 95.02.06 T5 1

$60 \mathrm{lam}$

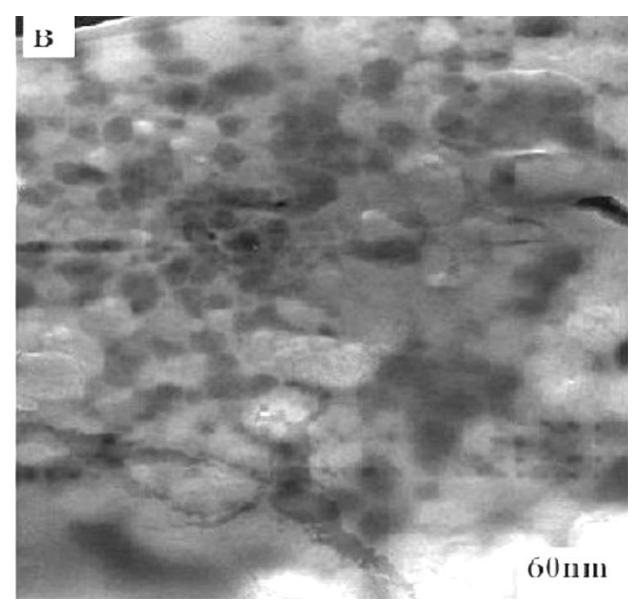

\section{RESULTS AND DISCUSSION}

Characterization of $\mathrm{CuO}$ NPs. As shown in figure 1, the SEM images of synthesized CuO NPs confirmed - both powders were aggregated and the apparent average sizes were 30 and $60 \mathrm{~nm}$. Also, the zeta sizer of CuO NPs by DLS confirmed their sizes as shown in figure 2 . 
$\left(\mathrm{IC}_{50}\right)$ was counted as the concentration required to inhibit the growth of B92 cancer cells in the culture medium by $50 \%$ compared to the untreated cells. The $\mathrm{IC}_{50}$ of nanoparticles with the size of $30 \mathrm{~nm}$ were $12.01 \pm 1.9$ and for nanoparticles with $60 \mathrm{~nm}$ was $9.17 \pm 3.3$. The $\mathrm{IC}_{50}$ decreased by increasing of particle size, but the decrease was non-significantly $(\mathrm{p}>0.05)$.

Quantification of apoptosis by double staining using acridine orange and propidium iodide. The fluorescence microscopic study was used to determine whether the cytotoxic effect of CuONPs was related to the induction of apoptosis. In cell populations, the viable cell possesses uniform bright green nucleus with diffused chromatin (exclude of PI), whereas early apoptotic cells showed bright green areas of condensed chromatin in the nucleus, and necrotic cells in a uniform bright red nucleus with non-condensed chromatin (include of PI). However, cells exposed to CuONPs at $20 \mu \mathrm{g} / \mathrm{ml}$ concentration exhibited more condensed chromatin, fragmented nuclei, and appearance of apoptotic bodies as displayed in figure 4 . The percentages of the apoptotic cell were evaluated at different concentrations of $\mathrm{CuO}$ NPs treated samples $(0,5,10$ and $20 \mu \mathrm{g} / \mathrm{ml}$ ). The percentage of apoptotic cells showed concentration-dependent manner, in a way that, the possible induction of apoptosis enhanced as the concentration of treatment increased (Figure 5). Results showed that morphological identification of apoptosis and apoptotic DNA fragmentation has been developed with the use of $\mathrm{CuO}$ NPs.

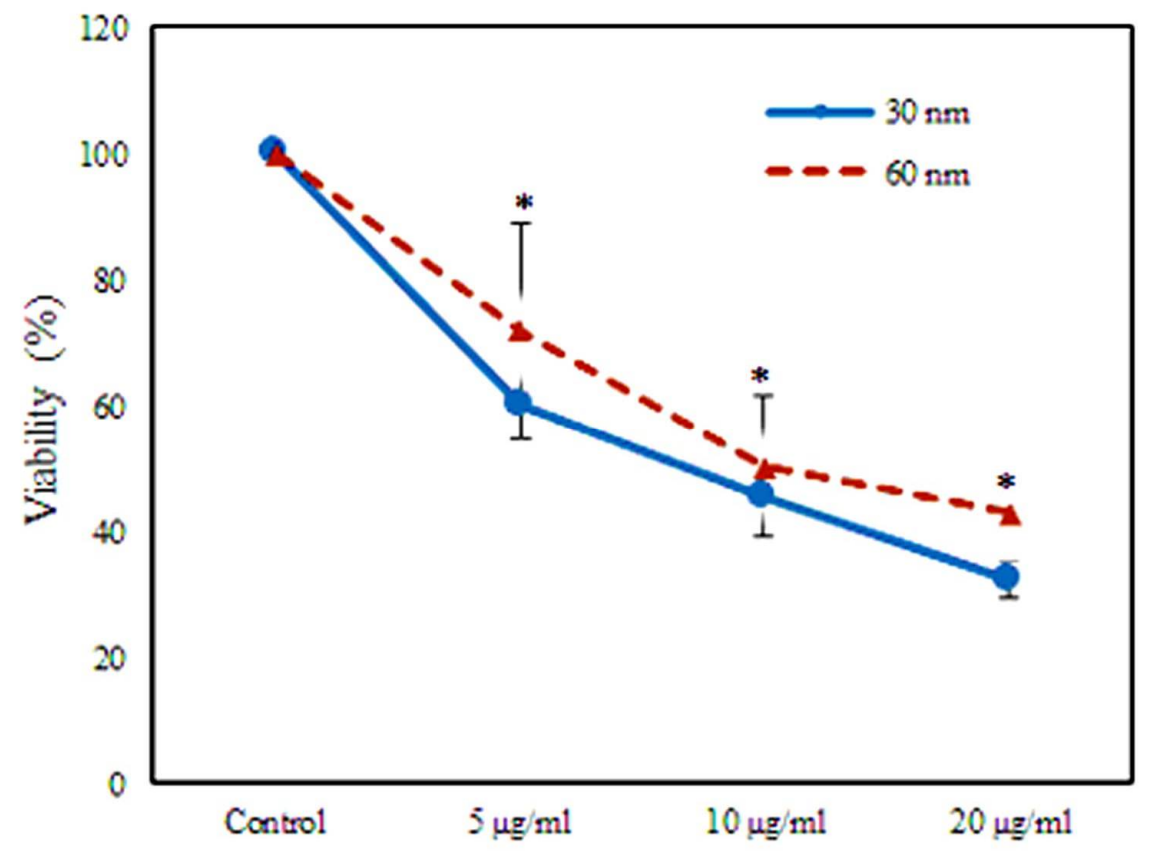

Figure 3. Cytotoxicity in different concentrations of $\mathrm{CuO} \mathrm{NPs} \mathrm{with} \mathrm{the} \mathrm{sizes} \mathrm{of} 30$ and $60 \mathrm{~nm}$ by MTT assay. $\square$ represents a significant difference from the control ( $\mathrm{p}<0.05)$.

Nanoparticles have some physicochemical properties through their size which make them chemically more reactive in possessing biological activities that can be either desirable as drug delivery or undesirable by induction of oxidative stress or cellular dysfunction. ${ }^{24}$ A glioma is an aggressive form of brain cancer that starts from transformed of glial cells. ${ }^{19}$ Limitations of current therapies necessitate an effective, inexpensive and non-toxic treatments with slight side effects that are accepted 
by people. The ability of cancer cells to avoid apoptosis and continue to propagate to make metal oxide nanoparticles as a demand for continuing new anti-cancer drugs researches ${ }^{20}$. Due to antimicrobial properties, $\mathrm{CuO}$ NPs are a right choice for being used in products such as textiles, intrauterine devices, food contact materials and wood preservation, therefore, these are widely manufactured and used. ${ }^{8}$ Earlier studies showed potent cytotoxic, genotoxic and toxicological activities of CuNPs and even, toxic effects of various

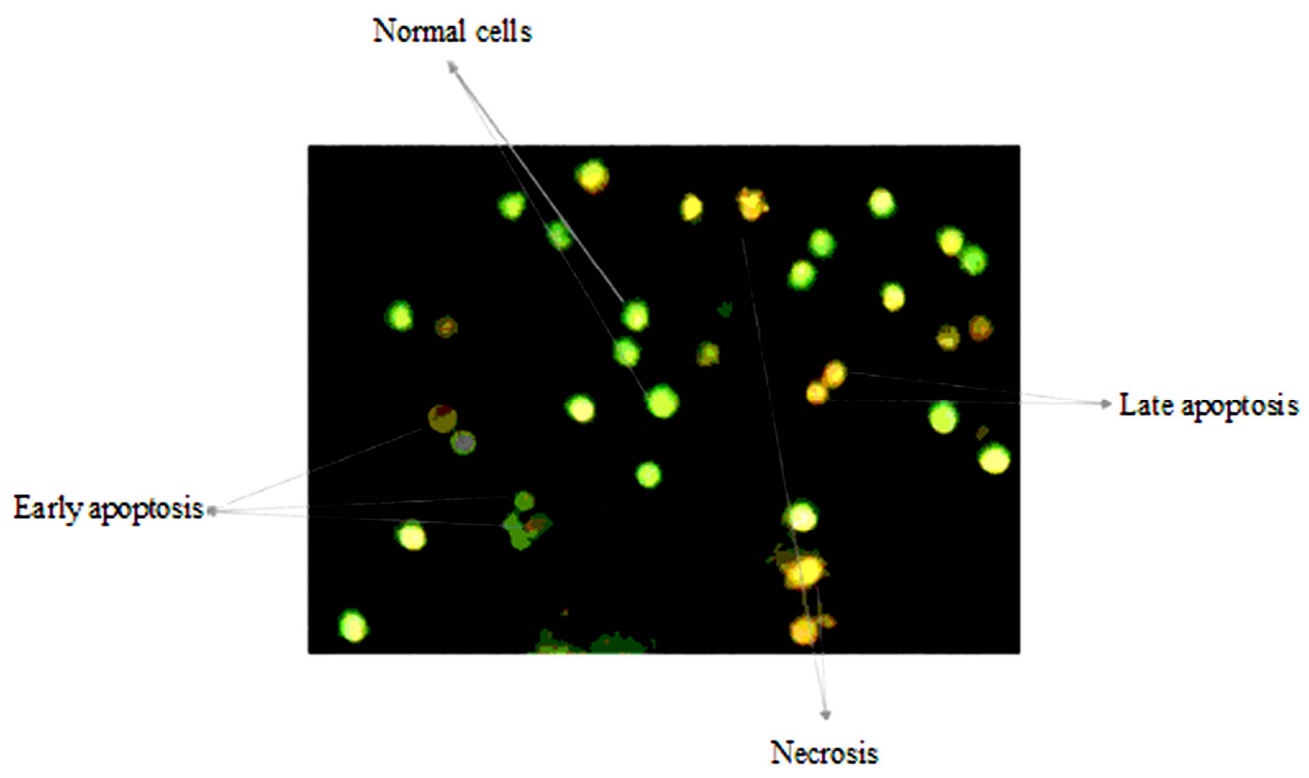

Figure 4. Apoptotic morphological observation at $20 \mu \mathrm{g} / \mathrm{ml}$ concentration with acridineorange/ propidium iodide staining by fluorescence microscope (40x). The cells were seeded in 6-well plates and were treated with CuO NPs $(0,5,10$ and $20 \mu \mathrm{g} / \mathrm{ml}$ ) for 24 hours-hrs.

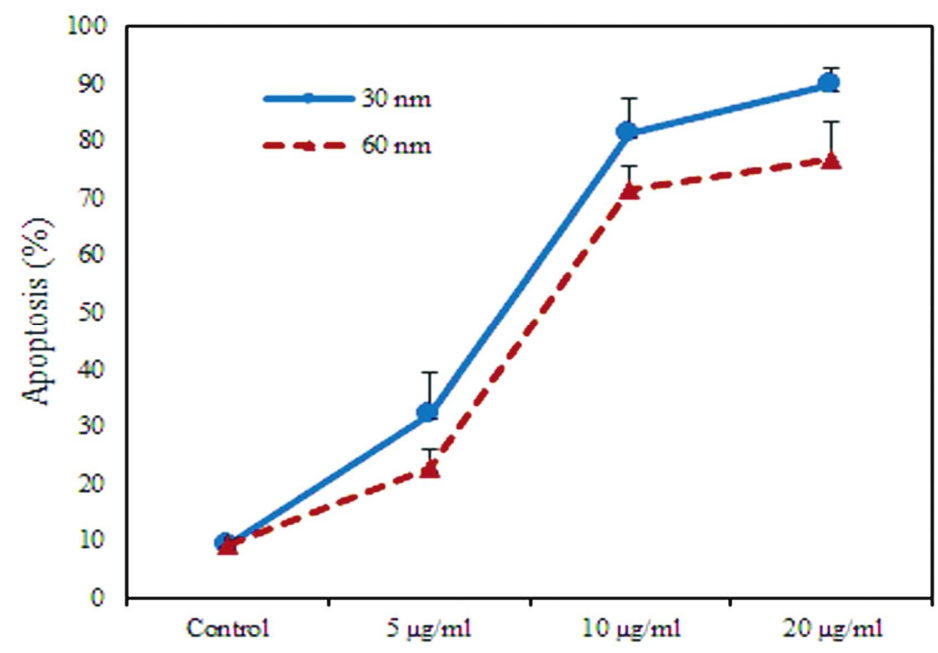

Figure 5. Determination of apoptosis in different concentrations of CuO NPs treated samples with 30 and $60 \mathrm{~nm}$ sizes of NPs.

types of nanoparticles in C6 glioma cancer cells. $^{15,22,25}$ So, in the present study, two sizes of $\mathrm{CuO}$ NPs (30 and $60 \mathrm{~nm}$ ) were synthesized by an alcothermal method and were used in different concentration to evaluate their anticancer activity in B92 glial cancer cells. Characterization of 
nanoparticles is essential before assessing the cytotoxicity since any changes in their characterization can have an effect on cellular responses upon exposure. ${ }^{26,27}$ Thus, we first characterized the synthesized $\mathrm{CuO}$ NPs for better interpretation of results. The SEM images and zeta size reconfirmed the 30 and $60 \mathrm{~nm}$ sizes of $\mathrm{CuO}$ NPs, respectively.

The results of MTT assay was used for studying the cytotoxicity of two sizes of CuO NPs and showed that both $\mathrm{CuO}$ NPs (30 and $60 \mathrm{~nm})$ induces cytotoxicity in B92 cancer cells after $24 \mathrm{hrs}$ of exposure in a concentration-dependent manner. In a way that exposure to $\mathrm{CuO}$ NPs had a significant cytotoxic effect with the sizes tested when compared to unexposed control and the smaller size and higher concentration exerted the maximum cytotoxic effects. Our findings are in agreement with previous studies. ${ }^{13-15,28}$ Although, there is a significant variation in the ability of both particles to alter cell cytotoxicity, the differences in cytotoxicity of each concentration of CuO-NPs is not certain as previously reported for somato sensory neurons of a rat in cell culture. ${ }^{29}$ The $\mathrm{IC}_{50}$ decreased by increasing particle size, however, the decrease was nonsignificant. This suggests that augmentation may not have any impact on their cytotoxicity in vitro state.

Apoptosis and necrosis are two distinct mechanisms responsible for cell death, but induction of apoptosis in tumor cells is a vital and useful anticancer mechanism. Apoptotic cells are distinguished by altering morphological, molecular and biochemical properties and necrosis produces a leakage of cell content. ${ }^{30,31}$ A research illustrated that $\mathrm{CuO}$ NPs induces the typical appearance of characteristic modifications for apoptosis in cells. ${ }^{13}$ To quantitate apoptosis, AO staining was done to measure apoptosis induced by various concentrations of $\mathrm{CuO}$ NPs. AO/PI was used to distinguishing apoptosis from necrosis. The fluorescence microscopic study showed the condensation of chromatin and reduction in cell volume follows $\mathrm{CuO}$ NPs treatment. Apoptotic features are characterized by aggregated chromatin and condensed cytoplasm and occurred in the CuO NPs-treated rat cancer cells.

In conclusion, cellular apoptosis was affected by the presence of $\mathrm{CuO}$ NPS. By increasing the particle size, cellular apoptosis was developed. Although, exposure to $30 \mathrm{~nm}$ and $60 \mathrm{~nm}$ sizes had cytotoxic effects in cancer cells, it seems that augmentation may not have any impact on their in vitro cytotoxicity. Further investigations are required to better assess the biocompatibility and biosafety of $\mathrm{CuO}$ NPs for in vivo and in vitro conditions.

\section{ACKNOWLEDGEMENTS}

The authors would like to thank Mr. Aliyariat immunology laboratory of veterinary faculty, Urmia University. This work has been done at Urmia University, Iran.

\section{REFERENCES}

1. Sun, X., Liu, Z., Welsher, K., Robinson, J. T., Goodwin, A., Zaric, S. and Dai, H. 2008. Nano-graphene oxide for cellular imaging and drug delivery. Nano Res. 1, 203-212.

2. Liu, Z., Chen, K., Davis, C., Sherlock, S., Cao, Q., Chen, X. and Dai, H. 2008. Drug delivery with carbon nanotubes for in vivo cancer treatment. Cancer res. 68, 6652-6660.

3. Wu, Y. N., Chen, D. H., Shi, X. Y., Lian, C. C., Wang, T. Y., Yeh, C. S., Ratinac, K. R., Thordarson, P., Braet, F. and Shieh, D. B. 2011. Cancer-cell-specific cytotoxicity of nonoxidized iron elements in iron core-gold shell NPs. Nanomedicine 7, 420-427.

4. Lee, S. H., Kim, B. H., Na, H. B. and Hyeon, T. 2014. Paramagnetic inorganic nanoparticles as T1 MRI contrast agents, Wiley interdisciplinary reviews. Nanomed. Nanobiotechnol. 6, 196-209.

5. Elsaesser, A. and Howard, C. V. 2012. Toxicology of nanoparticles, Adv. Drug. Deliv. Rev. 64, 129-137.

6. Sorenson, J. R . 1992. Use of essential metalloelement complexes or chelates in biological studies. Free Radic. Biol. Med. 13, 593-594.

7. Arredondo, M. and Nunez, M. T. 2005. Iron and copper metabolism. Mol. Aspects Med. 26, 313-327.

8. Delgado, K., Quijada, R., Palma, R. and Palza, H. 2011. Polypropylene with embedded copper metal or copper oxide nanoparticles as a novel plastic antimicrobial agent. Lett. Appl. Microbiol. 53, 50-54.

9. Midander, K., Cronholm, P., Karlsson, H. L., Elihn, K., Moller, L., Leygraf, C. and Wallinder, I. O. 2009. Surface characteristics, copper release, and toxicity of nano- and micrometer-sized copper and copper(II) oxide particles: a cross-disciplinary study. Small 5, 389-399. 
10. Chen, Z., Meng, H., Xing, G., Chen, C., Zhao, Y., Jia, G., Wang, T., Yuan, H., Ye, C., Zhao, F., Chai, Z., Zhu, C., Fang, X., Ma, B. and Wan, L. 2006. Acute toxicological effects of copper nanoparticles in vivo. Toxicol. Lett. 163, 109-120.

11. Lee, J. H., Huh, Y. M., Jun, Y. W., Seo, J. W., Jang, J. T., Song, H. T., Kim, S., Cho, E. J., Yoon, H. G., Suh, J. S. and Cheon, J. 2007. Artificially engineered magnetic nanoparticles for ultra-sensitive molecular imaging. Nat. Med.13, 95-99.

12. Gnanavel, V., Palanichamy, V. and Roopan, S. M. 2017. Biosynthesis and characterization of copper oxide nanoparticles and its anticancer activity on human colon cancer cell lines (HCT-116). J. Photochem. Photobiol. B. 171, 133-138

13. Shafagh, M., Rahmani, F., and Delirezh, N. 2015. CuO nanoparticles induce cytotoxicity and apoptosis in human K562 cancer cell line via mitochondrial pathway, through reactive oxygen species and P53. Iran J. Basic. Med. Sci. 18, 993-1000.

14. Siddiqui, M. A., Alhadlaq, H. A., Ahmad, J., Al-Khedhairy, A. A., Musarrat, J., and Ahamed, M. 2013. Copper oxide nanoparticles induced mitochondria mediated apoptosis in human hepatocarcinoma cells. PloS one 8, e69534.

15. Joshi, A., Rastedt, W., Faber, K., Schultz, A. G., Bulcke, F. and Dringen, R. 2016. Uptake and Toxicity of Copper Oxide Nanoparticles in C6 Glioma Cells. Neurochem. Res. 41, 3004-3019.

16. Ude, V. C., Brown, D. M., Viale, L., Kanase, N., Stone, V. and Johnston, H. J. 2017. Impact of copper oxide nanomaterials on differentiated and undifferentiated Caco-2 intestinal epithelial cells; assessment of cytotoxicity, barrier integrity, cytokine production and nanomaterial penetration. Part Fibre Toxicol. 14, 31.

17. Jose, G. P., Santra, S., Mandal, S. K. and Sengupta, T. K. 2011. Singlet oxygen mediated DNA degradation by copper nanoparticles: potential towards cytotoxic effect on cancer cells. J. Nanobiotechnology 9, 9.

18. Kumaran, R. S., Choi, Y. K., Kim, H. J. and Kim, K. J. 2014. Quantitation of oxidative stress gene expression in MCF-7 human cell lines treated with water-dispersible $\mathrm{CuO}$ nanoparticles. Appl. Biochem. Biotechnol. 173, 731-740.

19. Maher, E. A., Furnari, F. B., Bachoo, R. M., Rowitch, D. H., Louis, D. N., Cavenee, W. K. and DePinho, R. A. 2001. Malignant glioma: genetics and biology of a grave matter. Genes. Dev. 15, 1311-1333.

20. Sherr, C. J. 2004. Principles of tumor suppression. Cell 116, 235-246.

21. Trejo-Solis, C., Jimenez-Farfan, D., Rodriguez-Enriquez, S., Fernandez-Valverde, F., Cruz-Salgado, A., Ruiz-Azuara, L. and Sotelo, J. 2012. Copper compound induces autophagy and apoptosis of glioma cells by reactive oxygen species and JNK activation. BMC Cancer. 12, p.156.
22. Shevtsov, M. A., Nikolaev, B. P., Yakovleva, L. Y., Parr, M A., Marchenko, Y. Y., Eliseev, I., Yudenko, A., Dobrodumov, A. V., Zlobina, O., Zhakhov, A., Ischenko, A. M., Pitkin, E. and Multhoff, G. 2015. 70-kDa heat shock protein coated magnetic nanocarriers as a nanovaccine for induction of anti-tumor immune response in experimental glioma, J. Contr. Rel. 220, 329-340.

23. Mosmann, T. 1983. Rapid colorimetric assay for cellular growth and survival: application to proliferation and cytotoxicity assays. J. Immunol. Methods $\mathbf{6 5}, 55-63$.

24. Medina, C., Santos-Martinez, M. J., Radomski, A., Corrigan, O.I. and Radomski, M. W. 2007. Nanoparticles: pharmacological and toxicological significance. $\mathrm{Br} . \quad \mathrm{J}$. Pharmacol. 150, 552-558.

25. Zhang, Y., Yu, J., Zhang, L., Cai, J., Cai, D. and Lv, C. 2016 Enhanced anti-tumor effects of doxorubicin on glioma by entrapping in polybutylcyanoacrylate nanoparticles. Tumour Biol. 37, 2703-2708.

26. Murdock, R. C., Braydich-Stolle, L., Schrand, A. M., Schlager, J. J. and Hussain, S. M. 2008. Characterization of nanomaterial dispersion in solution prior to in vitro exposure using dynamic light scattering technique. Toxicol. Sci. 101, 239-253.

27. Laurent, S., Forge, D., Port, M., Roch, A., Robic, C., Vander Elst, L. and Muller, R. N. 2008. Magnetic iron oxide nanoparticles: synthesis, stabilization, vectorization, physicochemical characterizations, and biological applications. Chem. Rev. 108, 2064-2110.

28. Shaligram, S. and Campbell, A. 2013. Toxicity of copper salts is dependent on solubility profile and cell type tested. Toxicol. In Vitro. 27, 844-851.

29. Prabhu, B. M., Ali, S. F., Murdock, R. C., Hussain, S. M. and Srivatsan, M. 2010. Copper nanoparticles exert size and concentration dependent toxicity on somatosensory neurons of rat. Nanotoxicology 4, 150-160.

30. Darzynkiewicz, Z., Juan, G., Li, X., Gorczyca, W., Murakami, T. and Traganos, F. 1997. Cytometry in cell necrobiology: analysis of apoptosis and accidental cell death (necrosis). Cytometry 27, 1-20.

31. Tatton, N. A. and Rideout, H. J. 1999. Confocal microscopy as a tool to examine DNA fragmentation, chromatin condensation and other apoptotic changes in Parkinson's disease. Parkinsonism Rel. Disord. 5, 179-186. 